\title{
APLIKASI FUZZY INFERENCE SYSTEM METODE MAMDANI UNTUK REKOMENDASI PEMILIHAN BIDANG KAJIAN PADA MAHASISWA PROGRAM STUDI MATEMATIKA UNSOED
}

\author{
Yusuf Nur Assegaf dan Mutia Nur Estri \\ Jurusan MIPA Fakultas Sains dan Teknik Universitas Jenderal Soedirman \\ Email: gogozhenk@gmail.com,mutia_ne_yusuf@yahoo.com
}

\begin{abstract}
This paper discusses about Fuzzy Inference System (FIS) using Mamdani method to recommend the choice of major field for students of Mathematics department Unsoed. The method of Mamdani consist of a fuzzification, an application of the implication functions, composition of rules, and defuzzification. The input of fuzzification is score of some compulsary subjects for each field. The application of implication function used min implication, while the composition rule is based on PAP in Mathematic department Unsoed. The defuzzification required score of some compulsary subjects for each field as input and the recommend score of each major field as output. Based on the output, a student of Mathematic department Unsoed is able to choose a major field according to his/her score.
\end{abstract}

Keyword : Fuzzy Inference System (FIS), the method of Mamdani, fuzzification, defuzzification.

ABSTRAK. Paper ini membahas Fuzzy Inference System (FIS) metode Mamdani yang diaplikasikan untuk merekomendasikan pemilihan bidang kajian pada mahasiswa Prodi Matematika Unsoed. Tahapan metode Mamdani meliputi fuzzifikasi, aplikasi fungsi implikasi, komposisi aturan, dan defuzzifikasi. Input fuzzifikasi berupa nilai mata kuliah pendukung masing-masing bidang kajian. Aplikasi fungsi implikasi yang digunakan adalah implikasi min. Komposisi aturan disusun berdasarkan pada penilaian acuan patokan yang berlaku di Prodi Matematika Unsoed. Tahap defuzzifikasi memerlukan input berupa nilai angka mata kuliah pendukung masing-masing bidang kajian dan output berupa tingkat rekomendasi. Berdasarkan tingkat rekomendasi yang diperoleh, mahasiswa diharapkan dapat memilih bidang kajian yang sesuai dengan nilai mata kulianya.

Kata kunci : Fuzzy Inference System (FIS), metode Mamdani, fuzzifikasi, defuzzifikasi.

\section{Pendahuluan}

Matematika merupakan salah satu disiplin ilmu yang dipelajari dari tingkat dasar sampai tingkat universitas. Di tingkat universitas, matematika tidak hanya menjadi salah satu mata kuliah dasar saja, tetapi juga dipelajari lebih mendalam di salah satu program studi atau jurusan, yaitu Program Studi (Prodi) atau Jurusan Matematika. Di Universitas Jenderal Soedirman (Unsoed), Prodi Matematika 
memiliki 4 pilihan bidang kajian, yaitu bidang kajian matematika murni, statistika, matematika terapan, dan komputasi. Mulai tahun kedua, mahasiswa Prodi Matematika Unsoed diberikan kebebasan untuk memilih 2 bidang kajian yaitu bidang kajian mayor dan minor sesuai minat dan kemampuan mereka. Pemilihan 2 bidang kajian ini dimaksudkan sebagai persiapan awal dalam proses pemilihan topik tugas akhir yang akan diambil pada tahun keempat. Bidang kajian mayor yang nantinya akan dijadikan topik dalam tugas akhir, sedangkan bidang kajian minor sebagai cadangan apabila mahasiswa ingin beralih ke pilihan bidang kajian diluar bidang kajian mayor. Jumlah minimal mata kuliah pilihan bidang kajian mayor yang harus diambil adalah 15 SKS, sedangkan untuk bidang kajian minor adalah 12 SKS (Universitas Jenderal Soedirman, 2010).

Salah satu alat yang dapat membantu pemilihan bidang kajian berdasarkan kombinasi nilai mata kuliah adalah sistem pengambilan keputusan pada fuzzy yaitu FIS (Fuzzy Inference System) metode Mamdani. Dengan menggunakan FIS ini diharapkan dapat membantu merokomendasikan pemilihan bidang kajian pada mahasiswa Prodi Matematika UNSOED.

\section{Fuzzy Inference System Metode Mandani}

Metode Mamdani merupakan suatu metode FIS yang dapat diterapkan pada input data yang berupa variabel linguistik, yaitu variabel yang bersifat alamiah atau diperoleh dari manusia. Output yang diperoleh dengan metode Mamdani berupa himpunan fuzzy. Tahapan-tahapan yang dilakukan adalah sebagai berikut:

\subsection{Pembentukan Himpunan Fuzzy}

Program yang dibuat untuk menentukan rekomendasi pemilihan bidang kajian pada mahasiswa Prodi Matematika Unsoed dibagi dalam 4 FIS, dengan masing-masing FIS memiliki nilai input dan output yang berbeda tetapi langkah konstruksi FIS yang sama. Masing-masing FIS terdiri atas nilai akhir 3 mata kuliah pendukung bidang kajian sebagai variabel input dan salah satu bidang kajian sebagai variabel output. Nilai akhir pada mata kuliah pendukung bidang kajian yang digunakan adalah nilai akhir mata kuliah yang berupa nilai angka. 
Variabel input untuk FIS dengan variabel output Matematika Murni adalah nilai akhir untuk mata kuliah Aljabar Linear Elementer (ALE), Aljabar Linear (AL), dan Logika Matematika dan Himpunan (LMH). Variabel input untuk FIS dengan variabel output Komputasi adalah nilai akhir untuk mata kuliah Logika Matematika dan Himpunan (LMH), Pemrograman Komputer (PK), dan Matematika Diskret (MD). Variabel input untuk FIS dengan variabel output Matematika Terapan adalah nilai akhir untuk mata kuliah Matematika Diskret (MD), Riset Operasi I (RO1), dan Persamaan Differensial Biasa (PDB). Sementara itu variabel input untuk FIS dengan variabel output Statistika adalah nilai akhir untuk mata kuliah Statistika Elementer (SE), Kalkulus Peubah Banyak (KPB), dan Teori Peluang (TP). Pemilihan variabel-varibael pada masingmasing bidang kajian didasarkan pada kebutuhan mata kuliah yang harus dikuasai apabila memilih bidang kajian tersebut

Variabel input dan output pada FIS merupakan suatu himpunan fuzzy yang memiliki semesta pembicaraan. Semesta pembicaraan yang digunakan pada FIS dapat dilihat pada Tabel 2.1

Tabel 2.1 Semesta pembicaraan

\begin{tabular}{|c|c|c|c|}
\hline Fungsi & Nama Variabel & Notasi & $\begin{array}{c}\text { Semesta } \\
\text { Pembicaraan }\end{array}$ \\
\hline \multirow{10}{*}{ Input } & Aljabar Linear Elementer & ALE & {$[0,100]$} \\
\hline & Aljabar Linear & AL & {$[0,100]$} \\
\hline & Logika Matematika dan Himpunan & LMH & {$[0,100]$} \\
\hline & Pemrograman Komputer & PK & {$[0,100]$} \\
\hline & Matematika Diskret & MD & {$[0,100]$} \\
\hline & Riset Operasi 1 & RO1 & {$[0,100]$} \\
\hline & Persamaan Differensial Biasa & PDB & {$[0,100]$} \\
\hline & Statistika Elementer & SE & {$[0,100]$} \\
\hline & Kalkulus Peubah Banyak & KPB & {$[0,100]$} \\
\hline & Teori Peluang & $\mathrm{TP}$ & {$[0,100]$} \\
\hline \multirow{4}{*}{ Output } & Matematika Murni & MURNI & {$[0,100]$} \\
\hline & Komputasi & KOMPUTASI & {$[0,100]$} \\
\hline & Matematika Terapan & TERAPAN & {$[0,100]$} \\
\hline & Statistika & STATISTIKA & {$[0,100]$} \\
\hline
\end{tabular}


Masing-masing variabel input, memiliki 4 fungsi keanggotaan, yaitu fungsi keanggotaan kurang dengan lingkup [0,56], fungsi keanggotaan cukup dengan lingkup [46,80], fungsi keanggotaan baik dengan lingkup [56,90] dan fungsi keanggotaan sangat baik dengan lingkup $[66,100]$. Sementara itu, variabel output memiliki 2 fungsi keanggotaan yaitu fungsi keanggotaan tidak direkomendasikan dengan lingkup $[0,75]$ dan fungsi keanggotaan direkomendasikan dengan lingkup [46,100]. Pemilihan derajat keanggotan ini berdasarkan pada sistem PAP (Penilaian Acuan Patokan) yang diterapkan pada Prodi Matematika Unsoed seperti pada Tabel 2.2.

Tabel 2.2 Patokan Acuan Penilaian

\begin{tabular}{|c|c|}
\hline Indeks Nilai & Range Nilai \\
\hline A & $80.00<$ nilai $\leq 100.00$ \\
\hline B & $66.00<$ nilai $\leq 80.00$ \\
\hline C & $56.00<$ nilai $\leq 66.00$ \\
\hline D & $46.00<$ nilai $\leq 56.00$ \\
\hline E & $0 \leq$ nilai $\leq 46.00$ \\
\hline
\end{tabular}

Himpunan fuzzy yang dibuat untuk tiap-tiap variabel input dapat dilihat pada Tabel 2.3, sedangkan untuk variabel output dapat dilihat pada Tabel 2.4. Derajat keanggotaan $(\mu)$ untuk setiap himpunan fuzzy mempunyai interval antara 0 sampai 1. Nilai 0 menunjukkan tidak adanya keanggotaan (0\%) di dalam himpunan fuzzy, sedangkan nilai 1 menunjukkan keanggotaan mutlak (100\%) di dalam himpunan fuzzy.

Tabel 2.3 Himpunan input fuzzy

\begin{tabular}{|c|c|c|}
\hline \multicolumn{2}{|c|}{ Himpunan Input Fuzzy } & \multirow{2}{*}{ Lingkup } \\
\cline { 1 - 2 } Nama & Notasi & \\
\hline Kurang & K & {$[0,56]$} \\
\hline Cukup & C & {$[46,80]$} \\
\hline Baik & B & {$[56,90]$} \\
\hline Sangat Baik & S & {$[66,100]$} \\
\hline
\end{tabular}


Tabel 2.4 Himpunan output fuzzy

\begin{tabular}{|c|c|c|}
\hline \multicolumn{2}{|c|}{ Himpunan Output Fuzzy } & \multirow{2}{*}{ Lingkup } \\
\cline { 1 - 2 } Nama & Notasi & \\
\hline Tidak direkomendasikan & TIDAK & {$[0,75]$} \\
\hline Direkomendasikan & YA & {$[46,100]$} \\
\hline
\end{tabular}

\subsection{Konstruksi FIS}

Konstruksi FIS merupakan proses pengolahan variabel input menjadi variabel output. Pada metode Mamdani, konstruksi FIS terdiri dari proses pembentukan himpunan fuzzy (fuzzifikasi), aplikasi fungsi implikasi, penentuan komponen aturan, dan defuzzifikasi.

\subsubsection{Fuzzifikasi}

Proses fuzzifikasi merupakan proses terbentuknya himpunan fuzzy. Fungsi keanggotaan dari masing-masing varibel input dan output dapat dilihat pada persamaan berikut.

$$
\begin{aligned}
& \mu_{K}[x]= \begin{cases}1 ; & x \leq 46 \\
(56-x) /(56-46) ; & 46<x<56 \\
0 ; & x \geq 56\end{cases} \\
& \mu_{\mathrm{C}}[x]= \begin{cases}0 ; & x \leq 46 \text { atau } x \geq 80 \\
(x-46) /(56-46) ; & 46<x<56 \\
1 ; & 56 \leq x \leq 66 \\
(80-x) /(80-66) ; & 66<x<80\end{cases} \\
& \mu_{\mathrm{S}}[x]= \begin{cases}0 ; & x \leq 56 \text { atau } x \geq 90 \\
(x-56) /(68-56) ; & 56<x<68 \\
1 ; & 68 \leq x \leq 78 \\
(90-x) /(90-78) ; & 78<x<90\end{cases} \\
& \mu_{\mathrm{B}}[x]= \begin{cases}0 ; & x \leq 66 \\
(x-66) /(80-66) ; & 66<x<80 \\
1 ; & x \geq 80\end{cases} \\
& \mu_{\mathrm{TIDAK}}[x]= \begin{cases}1 ; & x \leq 30 \\
(75-x) /(75-30) ; & 30<x<75 \\
0 ; & x \geq 75\end{cases} \\
& \mu_{\mathrm{YA}}[x]= \begin{cases}0 ; & x \leq 46 \\
(x-46) /(80-46) ; & 46<x<80 \\
1 ; & x \geq 80\end{cases}
\end{aligned}
$$




\subsubsection{Penerapan Aturan Dasar Fuzzy}

Aturan dasar fuzzy merupakan suatu pernyataan kualitatif yang dibentuk dengan pernyataan IF THEN. Aturan fuzzy dalam pemilihan bidang kajian mahasiswa ditentukan berdasarkan kombinasi nilai dari masing-masing mata kuliah pendukung bidang kajian. Berdasarkan kombinasi tersebut, diperoleh 30 aturan untuk masing-masing bidang kajian. Berikut aturan dasar yang digunakan yang digunakan dalam bidang kajian Matematika Murni

[R1] IF ALE is K THEN MURNI is TIDAK

[R2] IF AL is K THEN MURNI is TIDAK

[R3] IF LMH is $\mathrm{K}$ THEN MURNI is TIDAK

[R4] IF ALE is $\mathrm{C}$ and AL is C and LMH is C THEN MURNI is TIDAK

[R5] IF ALE is $\mathrm{C}$ and AL is $\mathrm{C}$ and LMH is B THEN MURNI is TIDAK

[R6] IF ALE is $\mathrm{C}$ and AL is $\mathrm{C}$ and LMH is A THEN MURNI is TIDAK

[R7] IF ALE is $C$ and AL is B and LMH is C THEN MURNI is TIDAK

[R8] IF ALE is C and AL is B and LMH is B THEN MURNI is YA

[R9] IF ALE is C and AL is B and LMH is A THEN MURNI is YA

[R10] IF ALE is $C$ and AL is A and LMH is C THEN MURNI is TIDAK

[R11] IF ALE is C and AL is A and LMH is B THEN MURNI is YA

[R12] IF ALE is C and AL is A and LMH is A THEN MURNI is YA

[R13] IF ALE is B and AL is C and LMH is C THEN MURNI is TIDAK

[R14] IF ALE is B and AL is C and LMH is B THEN MURNI is YA

[R15] IF ALE is B and AL is C and LMH is A THEN MURNI is YA

[R16] IF ALE is B and AL is B and LMH is C THEN MURNI is YA

[R17] IF ALE is B and AL is B and LMH is B THEN MURNI is YA

[R18] IF ALE is B and AL is B and LMH is A THEN MURNI is YA

[R19] IF ALE is B and AL is A and LMH is C THEN MURNI is YA

[R20] IF ALE is B and AL is A and LMH is B THEN MURNI is YA

[R21] IF ALE is B and AL is A and LMH is A THEN MURNI is YA

[R22] IF ALE is A and AL is C and LMH is C THEN MURNI is TIDAK

[R23] IF ALE is A and AL is C and LMH is B THEN MURNI is YA

[R24] IF ALE is A and AL is C and LMH is A THEN MURNI is YA

[R25] IF ALE is A and AL is B and LMH is C THEN MURNI is YA

[R26] IF ALE is A and AL is B and LMH is S THEN MURNI is YA

[R27] IF ALE is A and AL is B and LMH is A THEN MURNI is YA

[R28] IF ALE is A and AL is A and LMH is C THEN MURNI is YA

[R29] IF ALE is A and AL is A and LMH is B THEN MURNI is YA

[R30] IF ALE is A and AL is A and LMH is A THEN MURNI is YA

Aturan dasar yang digunakan yang digunakan dalam bidang kajian Komputasi, Statistika dan Matematika Terapan sama dengan aturan dasar yang digunakan pada bidang kajian Matematika Murni hanya variabel input dan outputnya diganti sesuai dengan masing-masing bidang kajian. 


\subsubsection{Aplikasi Fungsi Implikasi}

Fungsi implikasi yang digunakan dalam metode Mamdani adalah metode minimum. Fungsi implikasi $(\alpha)$ menyatakan suatu derajat keanggotaan yaitu nilai minimum dari ketiga input berdasarkan aturan yang sudah terbentuk. Berikut adalah dua contoh aplikasi fungsi implikasi dari aturan-aturan yang terbentuk.

$$
\begin{aligned}
\alpha_{1} & =\mu_{\mathrm{K} \_\mathrm{ALE}}[x] \\
\alpha_{6} & =\mu_{\mathrm{C} \_\mathrm{ALE}}[x] \wedge \mu_{\mathrm{C} \_\mathrm{AL}}[x] \wedge \mu_{\mathrm{S} \_\mathrm{LMH}}[x] \\
& =\min \left(\mu_{\mathrm{C} \_\mathrm{ALE}}[x] ; \mu_{\mathrm{C} \_\mathrm{AL}}[x] ; \mu_{\mathrm{S} \_\mathrm{LMH}}[x]\right)
\end{aligned}
$$

\subsubsection{Defuzzifikasi}

Metode yang digunakan pada proses defuzifikasi dalam penelitian ini adalah metode centroid dimana nilai outputnya diperoleh dengan mengambil titik pusat daerah fuzzy.

\section{Contoh Kasus}

Berikut adalah daftar nilai dari 5 mahasiswa Prodi Matematika Unsoed, yang dipilih untuk mewakili rekomendasi pemilihan masing-masing bidang kajian.

Tabel 2.4 Daftar nilai mahasiswa

\begin{tabular}{|c|c|c|c|c|c|c|}
\hline \multirow{2}{*}{ No } & \multirow{2}{*}{ Mata Kuliah } & \multicolumn{5}{|c|}{ Nilai Angka / Huruf } \\
\cline { 2 - 7 } & & Mhs 1 & Mhs 2 & Mhs 3 & Mhs 4 & Mhs 5 \\
\hline 1 & ALE & $73 / \mathrm{B}$ & $64 / \mathrm{C}$ & $77 / \mathrm{B}$ & $79 / \mathrm{B}$ & $78 / \mathrm{B}$ \\
\hline 2 & $\mathrm{AL}$ & $76 / \mathrm{B}$ & $65 / \mathrm{C}$ & $73 / \mathrm{B}$ & $76 / \mathrm{B}$ & $65 / \mathrm{C}$ \\
\hline 3 & $\mathrm{LMH}$ & $75 / \mathrm{B}$ & $60 / \mathrm{C}$ & $82 / \mathrm{A}$ & $60 / \mathrm{C}$ & $77 / \mathrm{B}$ \\
\hline 4 & PK & $70 / \mathrm{B}$ & $64 / \mathrm{C}$ & $70 / \mathrm{B}$ & $77 / \mathrm{B}$ & $76 / \mathrm{B}$ \\
\hline 5 & MD & $77 / \mathrm{B}$ & $64 / \mathrm{C}$ & $79 / \mathrm{B}$ & $91 / \mathrm{A}$ & $74 / \mathrm{B}$ \\
\hline 6 & RO1 & $72 / \mathrm{B}$ & $56 / \mathrm{C}$ & $69 / \mathrm{B}$ & $81 / \mathrm{A}$ & $70 / \mathrm{B}$ \\
\hline 7 & PDB & $70 / \mathrm{B}$ & $65 / \mathrm{C}$ & $78 / \mathrm{B}$ & $85 / \mathrm{A}$ & $60 / \mathrm{C}$ \\
\hline 8 & SE & $76 / \mathrm{B}$ & $65 / \mathrm{C}$ & $81 / \mathrm{A}$ & $76 / \mathrm{B}$ & $81 / \mathrm{A}$ \\
\hline 9 & KPB & $75 / \mathrm{B}$ & $65 / \mathrm{C}$ & $73 / \mathrm{B}$ & $73 / \mathrm{B}$ & $60 / \mathrm{C}$ \\
\hline 10 & TP & $77 / \mathrm{B}$ & $57 / \mathrm{C}$ & $78 / \mathrm{B}$ & $68 / \mathrm{B}$ & $76 / \mathrm{B}$ \\
\hline
\end{tabular}

Kelima mahasiswa tersebut ingin menentukan bidang kajian pilihan yang sesuai dengan nilai mata kuliah tersebut. 


\subsection{Konstruksi FIS Murni}

Konstruksi FIS untuk variabel output Murni untuk mahasiswa 1 adalah sebagai berikut.

a. Menentukan derajat keanggotaan masing-masing variabel.

i. Variabel input ALE

Berdasarkan Tabel 2.3, nilai 73 termasuk dalam fungsi keanggotaan C, B, dan $\mathrm{S}$ dengan derajat keanggotaan masing-masing dapat diperoleh dengan persamaan (2.2) dan (2.3) sebagai berikut.

$$
\begin{gathered}
\mu_{\mathrm{C} \_\mathrm{ALE}}[x]=\mu_{\mathrm{C} \_\mathrm{ALE}}[73]=(80-73) /(80-66)=7 / 14=0,5 \\
\mu_{\mathrm{B} \_\mathrm{ALE}}[x]=\mu_{\mathrm{B} \_\mathrm{ALE}}[73]=1 \\
\mu_{\mathrm{S} \_\mathrm{ALE}}[x]=\mu_{\mathrm{S} \_\mathrm{ALE}}[73]=(73-66) /(80-66)=7 / 14=0,5
\end{gathered}
$$

Dengan langkah yang sama, diperoleh derajat keanggotaan untuk variabel input AL dan LMH sebagai berikut.

ii. Variabel input AL

$$
\begin{aligned}
& \mu_{\mathrm{C} \_\mathrm{AL}}[x]=\mu_{\mathrm{C} \_\mathrm{AL}}[76]=(80-76) /(80-66)=4 / 14=0,2857 \\
& \mu_{\mathrm{B} \_\mathrm{AL}}[x]=\mu_{\mathrm{B} \_\mathrm{AL}}[76]=1 \\
& \mu_{\mathrm{S} \_\mathrm{AL}}[x]=\mu_{\mathrm{S} \_\mathrm{AL}}[76]=(76-66) /(80-66)=10 / 14=0,7143
\end{aligned}
$$

iii. Variabel input LMH

$$
\begin{aligned}
& \mu_{\text {C_LMH }}[x]=\mu_{\text {C_LMH }}[75]=(80-75) /(80-66)=5 / 14=0,3571 \\
& \mu_{\text {B_LMH }}[x]=\mu_{\text {B_LMH }}[75]=1 \\
& \mu_{\text {S_LMH }}[x]=\mu_{\text {S_LMH }}[75]=(75-66) /(80-66)=9 / 14=0,6429
\end{aligned}
$$

b. Penerapan Aturan dan Fungsi Implikasi

Salah satu aturan yang berpengaruh terhadap derajat keanggotaan pada (a) adalah sebagai berikut.

$$
\begin{aligned}
\alpha_{4} & =\mu_{\mathrm{C} \_ \text {ALE }}[x] \Lambda \mu_{\mathrm{C} \_ \text {AL }}[x] \Lambda \mu_{\mathrm{C} \_ \text {LMH }}[x] \\
& =\min (0,5 ; 0,2857 ; 0,6429)=0,2857
\end{aligned}
$$




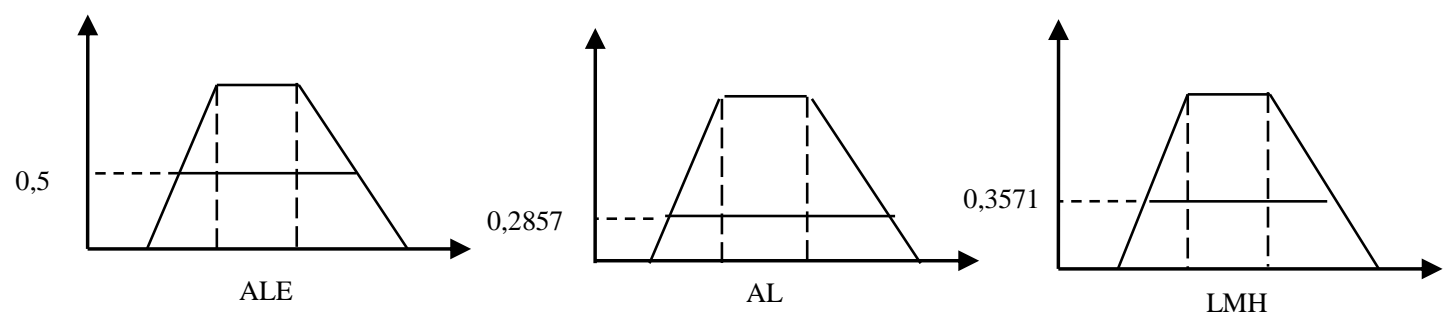

Gambar 2.1 Input fungsi implikasi aturan 4

Gambar 2.1 merupakan representasi kurva untuk masing-masing variabel input. Sementara itu, representasi kurva untuk variabel output ditunjukkan oleh Gambar 2.2.

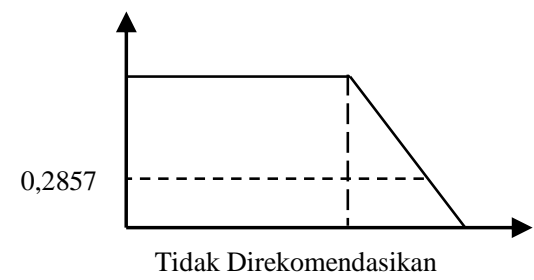

Gambar 2.2 Output fungsi implikasi aturan 4

c. Inferensi Aturan

Setelah diperoleh hasil aplikasi fungsi implikasi dari tiap aturan, maka diperoleh inferensi antar aturan dengan metode Max seperti pada Gambar 2.3.

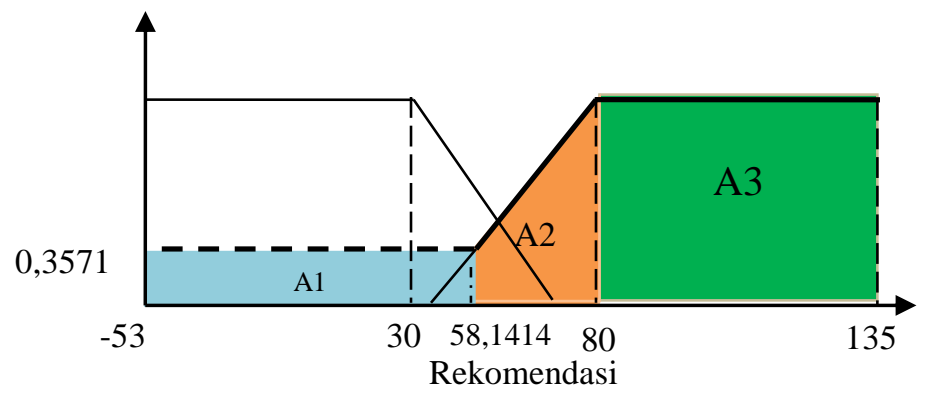

Gambar 2.3 Daerah fuzzy

Dari Gambar 2.3 diperoleh fungsi keanggotaan sebagai berikut.

$$
\mu[x]= \begin{cases}0,3571 ; & x \leq 58,1414 \\ (x-35) /(80-35) ; & 58,1414 \leq x \leq 80 \\ 1 ; & x \geq 80\end{cases}
$$

d. Defuzzifikasi

Proses defuzzifikasi menggunakan persamaan 2.7 dengan menghitung momen dan luas masing-masing daerah. 
Momen dan luas daerah pertama adalah

$$
\begin{aligned}
& \text { M1 }=\int_{-53}^{58,1414}(0,3571 z) d z=\left.\frac{0,3571 z^{2}}{2}\right|_{-53} ^{58,1414}=102,0274 \\
& \mathrm{~A} 1=\int_{-53}^{58,1414}(0,3571) d z=0,\left.3571 z\right|_{-53} ^{58,1414}=39,6886
\end{aligned}
$$

Momen dan luas daerah kedua adalah

$$
\begin{aligned}
& \mathrm{M} 2=\int_{58,1414}^{80} z\left(\frac{z-46}{80-46}\right) d z=\left.\frac{1}{34}\left(\frac{z^{3}}{3}-\frac{46 z^{2}}{2}\right)\right|_{58,1414} ^{80}=1050,0652 \\
& \mathrm{~A} 2=\int_{58,1414}^{80}\left(\frac{z-46}{80-46}\right) d z=\left.\frac{1}{34}\left(\frac{z^{2}}{2}-46 z\right)\right|_{58,1414} ^{80}=14,8322
\end{aligned}
$$

Momen dan luas daerah ketiga adalah

$$
\begin{aligned}
& \mathrm{M} 3=\int_{80}^{135} z d z=\left.\frac{z^{2}}{2}\right|_{80} ^{135}=5912,5 \\
& \mathrm{~A} 3=\int_{80}^{135} 1 d z=\left.z\right|_{80} ^{135}=55 .
\end{aligned}
$$

Jadi, diperoleh titik pusat

$$
z=\frac{M 1+M 2+M 3}{A 1+A 2+A 3}=\frac{102,0274+1050,0652+5912,5}{39,6886+14,8322+55}=64,505
$$

Berdasarkan titik pusat yang diperoleh, maka dapat disimpulkan bahwa seorang mahasiswa dengan spesifikasi nilai tersebut direkomendasikan untuk memilih bidang kajian matematika murni dengan tingkat rekomendasi 64,505. Untuk mempermudah perhitungan digunakan toolbox FIS pada Matlab dengan output seperti pada Tabel 2.5 . 
Tabel 2.5 Output FIS dengan MATLAB

\begin{tabular}{|c|c|c|c|c|c|}
\hline & Mhs 1 & Mhs 2 & Mhs 3 & Mhs 4 & Mhs 5 \\
\hline Murni & 64,746 & 30,871 & 75,258 & 68,054 & $\mathbf{7 5 , 2 5 8}$ \\
\hline Komputasi & 64,746 & 30,871 & $\mathbf{8 8 , 6 5 0}$ & 75,258 & 69,614 \\
\hline Terapan & 53,576 & 30,871 & 80,600 & $\mathbf{9 8 , 8 0 1}$ & 48,034 \\
\hline Statistika & $\mathbf{6 9 , 6 1 4}$ & 33,360 & 81,847 & 56,838 & 69,614 \\
\hline
\end{tabular}

Dari Tabel 2.5, dapat disimpulkan bahwa mahasiswa 1 direkomendasikan untuk memilih bidang kajian Statistika dengan tingkat rekomendasi 69,614. Mahasiswa 2 tidak direkomendasikan untuk memilih bidang kajian manapun. Hal ini dikarenakan semua nilai mata kuliah mahasiswa 2 belum cukup baik, untuk itu perlu dilakukan perbaikan nilai terlebih dahulu sebelum menentukan bidang kajian yang sesuai untuk mahasiswa tersebut. Sementara itu, mahasiswa 3 direkomendasikan untuk memilih bidang kajian Komputasi dengan tingkat rekomendasi 88,650. Mahasiswa 4 direkomendasikan untuk memilih bidang kajian Matematika Terapan dengan tingkat rekomendasi 98,801. Mahasiswa 5 direkomendasikan untuk memilih bidang kajian Matematika Murni dengan tingkat rekomendasi 75,258.

\section{Kesimpulan}

FIS metode Mamdani dapat diaplikasikan untuk rekomendasi pemilihan bidang kajian pada mahasiswa Matematika Unsoed. Hal ini dapat dilakukan dengan cara mendefinisikan 3 mata kuliah pendukung untuk masing-masing bidang kajian sebagai variabel input dan 4 bidang kajian sebagai variabel output. Variabel input memiliki 4 fungsi keanggotaan yaitu kurang $(\mathrm{K})$ dengan domain [0,56], cukup (C) dengan domain [46,80], baik (B) dengan domain [56,90], dan sangat baik (S) dengan domain [66,100]. Sementara itu, variabel output memiliki 2 fungsi keanggotaan yaitu tidak direkomendasikan (TIDAK) dengan nilai rekomendasi $[0,75]$ dan direkomendasikan (YA) dengan nilai rekomendasi $[46,100]$. Tingkat rekomendasi diperoleh dengan metode Mamdani menggunakan defuzzifikasi centroid. 


\section{Ucapan terima kasih}

Terima kasih diucapkan kepada Dr. Idha Sihwaningrum, M.Sc.St. yang banyak memberikan masukan dan saran pada proses penyusunan paper ini.

\section{DAFTAR PUSTAKA}

Djunaedi, M., Setiawan, E. dan Andista. F. W., Penentuan Jumlah Produksi Dengan Aplikasi Metode Fuzzy - Mamdani, Jurnal Ilmiah Teknik Industri, 4 (2), (2005), 95 - 104.

Kusumadewi, S. Analisis \& Desain Sistem Fuzzy Menggunakan Toolbox Matlab, Graha Ilmu, Yogyakarta, 2002.

Kusumadewi, S. dan Purnomo. H., Aplikasi Logika Fuzzy untuk Pendukung Keputusan. Graha Ilmu, Yogyakarta, 2010.

Pandjaitan, L. W., Dasar-Dasar Komputasi Cerdas, Penerbit Andi, Yogyakarta, 2007.

Sivanandam, S,N., Sumathi, S., dan Deepa, S.N., Introduction to Fuzzy Logic Using Matlab. Springer, German, 2007.

Universitas Jenderal Soedirman, Pedoman Unsoed 2010/2011 FST Jurusan MIPA, Universitas Jenderal Soedirman, Purwokerto,2010.. 